\title{
Leadership Tenacity and Public-School Superintendents
}

\author{
Barbara A. Klocko \\ Central Michigan University \\ Riley J. Justis \\ Central Michigan University \\ Elizabeth A. Kirby \\ Central Michigan University
}

\begin{abstract}
Leadership tenacity for school superintendents rests largely upon experience, grit, and subsequently resilience as they balance the pressures of the operational challenges of school operation with the instructional needs of the children they serve. Through this study, the authors identified the critical aspects of how effective superintendents may have developed and whether deliberate practice was evidenced in their experience. The superintendent's perseverance to doing what matters over an extended period of time and under challenging conditions contributes to leadership grit and resilience. Viewed through the lens of these superintendents, experience, grit, and resilience influence leadership tenacity interdependent, but not limited to the theory of deliberate practice and transformational leadership.
\end{abstract}

\section{Introduction}

At its most basic level, leadership tenacity is about working hard, and working smart over a sustained period of time. The purpose of this study is to better understand how superintendents develop grit, resilience, and tenacity while leading an educational enterprise. The superintendents in this study shared their insights on resilience and despair they experienced during the most recent challenging economic depression years in Michigan. Many of these superintendents did not fully embrace their tenacity, as it was veiled in their humility and passion for the work they do. School superintendents are faced with increasing pressures to adapt to mounting expectations from diverse populations, increase academic performance, balance operating budgets with reduced funding allocations, and respond to unpredictable social media commentary. Leadership grit, resilience, and tenacity for these superintendents were covert and, in most cases, did not strongly manifest until they had adequately worked hard, and worked smart over a sustained period of time.

\section{Leadership Tenacity}

Tenacity captures employees' cognitive ability to persevere and work hard in the face of challenging circumstances (Bakker \& Demerouti, 2007). For school superintendents, resiliency closely aligns with the complexity of the role itself, and the long-term challenges associated with economic recession. During the 2008-2012 school years, Michigan experienced a loss of 62,500 students (CEPI, 2009; 2012). This loss in enrollment affected not only student program 
development but also funds received by districts in the form of per pupil foundation allowance. This loss would lead school districts to reduce staff and cut budgets in a significant way. In 2015, nearly $36 \%$ of superintendents nationwide described their districts as declining in economic condition (Finnan \& McCord, 2017) similar to the financial turbulence faced by superintendents in Michigan.

The Michigan Education Association (MEA) reported nearly 70\% of teacher graduates were leaving the state to find jobs during those years, resulting in the current teacher shortage in Michigan schools. For the 2017-2018 school year, the Michigan Department of Education has declared 25 educational positions critical shortage areas for all districts in the state of Michigan. This shortage in Michigan echoes the shortages across the nation that have been negatively related to the financial downturn in the years of 2008-2012. These experiences have established the environment for leadership to be tested and for superintendents with leadership tenacity to rebound and commit to long-term goals.

A critical factor in leadership tenacity is grit, or perseverance and passion for long-term goals (Duckworth, Peterson, Matthews, \& Kelly, 2007). Murnieks, Cardon, Sudek and White (2016) reported that passion can be a marker to predict tenacity in leaders and must be recognized and cultivated. Tenacity reflects the persistence that employees exhibit during work, particularly when they confront challenging work situations (Baum \& Locke, 2004). More specifically, leadership tenacity is about the mindsets and skills that allow superintendents to look beyond short-term concerns to longer-term or higher-order goals, and withstand challenges and setbacks to persevere toward these goals. Superintendents who have a growth mindset about intelligence, learning goals, a higher-order purpose, and a sense that they belong within the culture of the school district may well show more grit in their work. Dweck (2006) claimed that people with a fixed mindset - those who believe that abilities are fixed - are far less likely to flourish than those with a growth mindset - those who believe that abilities can be developed through hard work, good strategies, and mentorship. Previous studies have shown that roughly $20 \%$ of individuals may fit partially into both groups, but most research has shown that individuals are equally divided into either mindset (Dweck \& Grant, 2008).

\section{Conceptual Framework}

In an earlier study, Klocko and Kirby (2014) presented a framework that included four skill sets essential for resilient school superintendents leading in challenging economic times-resilience thinking, building resilience capacity, resilience action skills, and building resilience capacity in others. The study was conducted in 2012 with a questionnaire that was distributed electronically to all superintendents in Michigan $(\mathrm{N}=570)$ with 173 participants The researchers have expanded this framework to more fully develop the concept of leadership tenacity. The harmful impact of challenging economic times on superintendent performance may be less noticeable because of the nature of the superintendents themselves. Superintendents' tenacity and passion for the work they do, helped to reframe this inquiry into the challenge of leading schools 


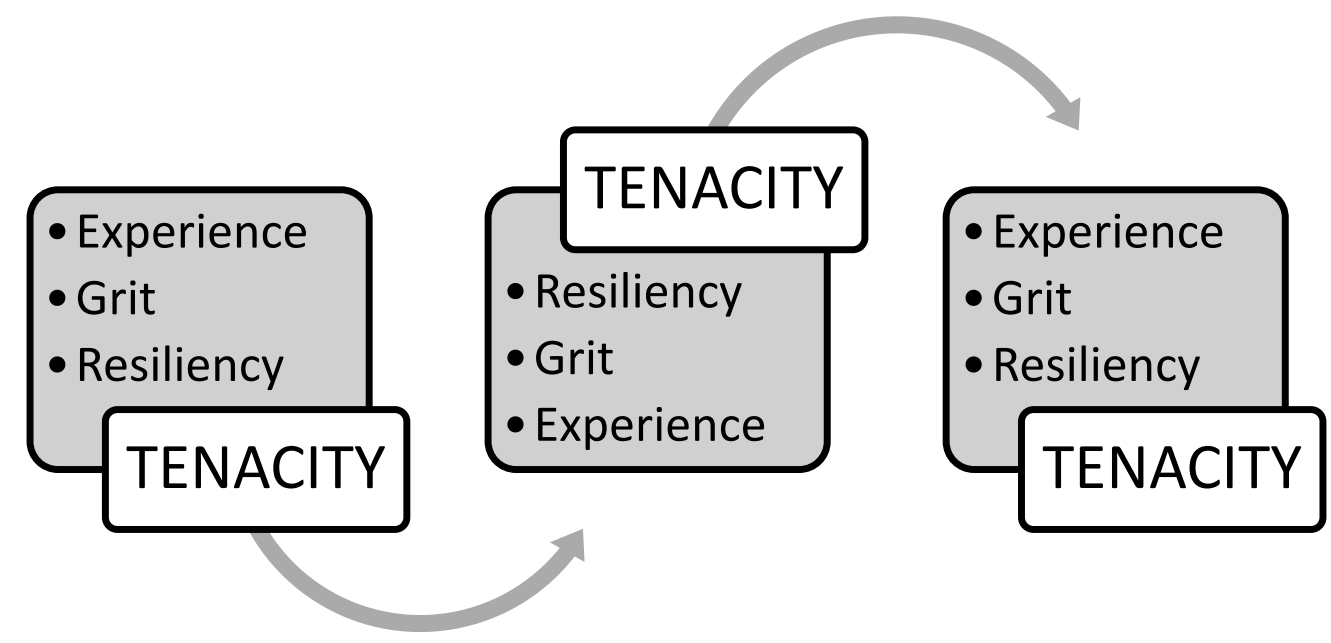

Figure 1. Conceptual framework of the developmental pathway for ongoing tenacity leadership development.

during crisis. In the development of a model explaining the developmental pathway for leadership tenacity, the researchers found leadership tenacity presented as the repeated sum outcomes of experience, grit, and resiliency as shown in Figure 1 and worked symbiotically with sustained practice. DeClercq and Belausteguigoitia (2017) posited that tenacity spurs successful leaders to action. We postulate that deliberate practice must be recursive in nature leading to enhanced levels of tenacity.

\section{Deliberate Practice Theory and Transformational Leadership}

Early researchers of deliberate practice theory believed that differences in performance can be explained by variances in past and current experiences (Ericsson, Krampe, \& TeschRomer, 1993). Ericsson et al. found "differences between expert performers and normal adults reflect a life-long period of deliberate effort to improve performance in a specific domain" ( $p$. 400). Deliberate practice can be regarded as "engagement in highly structured activities that are created specifically to improve performance in a domain through immediate feedback that require a high level of concentration, and that are not inherently enjoyable" (Hambrick, Oswald, Altmann, Meinz, Gobet, \& Campitelli, 2014, p. 35).

Gladwell (2008) redefined the impact of deliberate practice by quantifying focus on a single task for greater than 10,000 hours as a critical aspect of reaching proficiency. This concept of deliberate practice informs individuals and allows them to develop a depth of understanding through application. The idea that the individual must engage in practice for a given time affords superintendents the insight and experience that practice can provide and can define the most effective leaders as they reach collective thresholds of experience, grit, and resilience. Ericsson, Krampe, and Tesch-Romer (1993), original authors of the work Gladwell popularized, identified the duration of practice in a given field, rather than the 10,000 hours, as critical in the development of proficiency. Although slight variations exist, the researchers claimed that only through experiences representative of 10 years or 10,000 hours on a task will the individual reach 
a level of expert proficiency. A leader's experience becomes the key factor through which transformational leadership can be achieved.

The first phase of the inquiry aligned with Kouzes and Posner's (2012) transformational leadership model practices: challenging the process, inspiring a shared vision and enabling others to act. Kouzes and Posner's practices of modeling the way and encouraging the heart became operationalized for superintendents as they were immersed in grit and resilience building experiences (Kouzes \& Posner, 2012). The emerging concept that, only through experience can leadership become transformational is firmly positioned in the development of effective and transformative school leaders. Leaders in schools experience new and challenging events and interaction each day, many times with limited resources, training or knowledge. Experience emerges as a critical aspect for effective school leaders as they respond to challenge and adversity. The authors argue that although tenacity can be developed through sustained practice, tenacity may not be mastered by simply putting in their time as a superintendent. Due to the transiency inherent in the role of the superintendent, many superintendents hone their leadership savvy at the principal level and cannot acquire 10,000 hours of mastery of specific roles and responsibilities in the superintendency.

\section{Methodology}

In this qualitative phenomenological study, the authors systematically examined the beliefs of superintendents in Michigan regarding how they made meaning of their leadership during challenging economic times. This phase of data collection from 2015 included semistructured interviews of superintendents of school districts selected purposefully from rural areas of the state most strongly impacted by the economic crisis. The superintendents asked to participate served in rural public-school districts adjacent to automotive plants most closely associated with unemployment and job displacement. Participants were full-time superintendents $(\mathrm{n}=10)$ from rural school districts severely impacted by enrollment loss during the 2008-2012 recession and who consented to participate. This study explored collective attitudinal responses of rural superintendents and as such gender, tenure, and age were not demographic considerations in the identification of study participants.

Research methods such as interactive questioning within a semi-structured interview process along with member checks contributed to the trustworthiness of this study. A recently retired superintendent was trained and conducted the interviews to convey professional trust and elicit collegial responses from the participants. Interactive questioning allowed the researcher to ask probing follow-up questions within the context of the interview (Patton, 2002).

Trustworthiness within qualitative research was achieved by employing credible processes that enable credibility, transferability, and dependability (Shenton, 2004). Data were analyzed for patterns, themes, and categories. Interview transcripts were coded through initial coding (Saldana, 2009) followed by axial coding to refine, categorize, and determine relationships between codes using NVivo 11. Finally, key findings were determined from the identified themes. Each of the researchers in this study have worked in the public school learning environment as teachers, administrators, and professors. Their experience at all levels afforded them the ability to maintain an unbiased lens through which to analyze the responses of the participants. Since this study focused on the lived experiences of Michigan superintendents 
during challenging economic times, the findings may not be generalizable to the greater educational environments across the country.

\section{Findings}

The findings from this phenomenological qualitative inquiry endorse the three key findings from the researchers' previous quantitative analysis. Klocko and Kirby (2014) summarized:

1) Superintendents exhibit resilient qualities despite adverse conditions.

2) Strategies for building resilience capacity in themselves and others were related to district governance and contractual relationships.

3) Superintendents rarely express their feelings of anxiety or take the time to engage in stress-reducing activities.

In the second phase of this study, superintendents verified that they felt proficient in all the same areas that appeared in the initial study describing themselves highly proficient in terms of adaptability, confidence in their strengths and abilities, preparedness to handle problems associated with economic instability, and their ability to instill optimism in others. However, in the second phase of this inquiry, the researchers found a deeper thread woven through the narratives of superintendents as they faced unprecedented leadership challenges. The key findings from this qualitative inquiry can be summarized:

1) Resilience, grit, and superintendents' experience determine the leadership tenacity of the superintendent.

2) Leading during challenging times requires deliberate practice competencies and tenacity developed over time.

3) Superintendents who work hard, and work smart, over a sustained period of time will be regarded as successful leaders.

Leadership Experience. Passion for the work they do is foundational to the motivations of those who aspire to and become superintendents. One could argue that superintendents have spent their professional careers in preparation for the work they do every day. Their passion for work captures the joy that people derive from making significant time investments in work (Baum \& Locke, 2004). Baum and Locke further noted that passion is an emotional aspect of employees' approach to work, particularly the positive feelings they experience when they work hard. Supportive superintendents in this study appeared to demonstrate greater resiliency when faced with turbulent conditions. These superintendents generally had a strong sense of selfefficacy and were confident in their abilities to persevere and overcome challenges. Sommers (2009) proffered that resilient leaders are those who model resilient behavior in their personal and professional lives and have the capacity to promote and foster resiliency in others. One of the participants explained the balance of credibility and transparency that can only be developed by the leader through experience:

You're balancing your credibility versus your transparency, and knowing that things, when they first come out...often the fear factor comes about, which tends to aggrandize over time. If you don't address it, then you're hiding something. If you over-address it, you stand 


\section{a chance of having that not come true, and your credibility becomes vulnerable.}

Though the confidence of the leaders interviewed was evident, their ability to gauge the situation and the political and cultural impacts of statements and actions seemed to define each of the leadership experiences. Often leaders in the educational setting are regarded as experts through training, course work, or degree attainment. Based upon the concept of deliberate practice theory, leaders cannot rise to the level of leadership tenacity until they have grounded experience. This extensive experience allows the leader to meet the stress of the job with a systematic understanding of the challenges and rewards of the educational setting.

As a young leader, the pressure that is felt cannot be compartmentalized or contextualized, hindering the leader's ability to persevere. This understanding of the nature of leading in education was expressed by each of the superintendents. Leaders identified the differences and more clearly the ability to apply context to situational understanding as their years of experience grew. This function of effective leaders allows for value to be placed on the years and diversity of experience in the formation of effective leadership. One respondent identified the transition necessary in leadership style during times of conflict or financial strain on the district:

My leadership style has had to become... I think any time that you have financial troubles, you have to lean a little more towards your managerial style than a leadership style because it's a direct need. All of us want to be that leader and we really try to focus on that, and do less management but the issue is, is really when crisis mode hits, you have to become more managerial.

This transition identifies the fluidity of the effective leader, meeting the need of the leadership environment as a reflection of the times. This flexibility was echoed throughout the interviews with participants identifying their skills as important but their ability to flex and meet the need of the district as a critical aspect of their success in the job.

Leadership Grit. Superintendents with leadership tenacity rely upon their leadership strength and are solution-oriented in the face of adversity. They are strategic and understand that to maintain strength they must make a conscious effort to seek a healthy balance in their life and to reserve time for rest and renewal. In general, they have strong personal and professional support networks. They tend to be more highly motivated to utilize their skills and assets to improve outcomes. The issues that lead to individual burnout--lack of time, increased demands, assessment and accountability were all laced with a sense of efficacy that didn't emerge as strongly in our previous study, when superintendents were first witnessing the fallout from the economic depression. One superintendent acknowledged feelings of being "under the cloud of education... and we all feel like we have been rained on for a while now". This situational depression began to define the educational environment through the challenges of the economic downturn. The participant further credited the personal relationship he had with every staff member as a vital aspect of his leadership in previous roles, this same level of closeness was compromised in the feverish culture of educational leadership during challenging economic times. 
In this phenomenological study, we observed the superintendents who stay, the ones who chose to fight the good fight, those who overcame adversity to persist with perseverance and passion in pursuit of attaining long-term goals despite declining economic conditions. This cautiously optimistic superintendent queried, "I think we have bottomed out, I hope", authenticating the persistence of this superintendent, leading the district through the toughest times, allowing him to bring the district back to higher performance and educational outcomes. Each of the participants, recognizing the ongoing concerns in their districts, identified a focus on development and reform efforts. This focus gives the leaders direction and purpose, contributing to their grit, and ultimately contributing to their resiliency.

As identified by each of the study participants, the idea of working hard and smart is a concept that has developed over the duration of the superintendent's career. These skills and strategies are developed as reflections of the experiences of each district leader throughout their career as praxis. The concepts of grit and resiliency, as demonstrated through the beliefs and actions of the superintendents are developed through the opportunity to test and refine through experiences of the leader. Duckworth et al. clarified that grit requires an "emphasis on long term stamina rather than short-term intensity. The gritty individual not only finishes tasks at hand but pursues a given aim over years" (Duckworth et al., 2007, p. 1089).

Tenacious leaders facilitate change, work diligently, and persevere through opposition. Because of the trust this superintendent acquired as she came up through the ranks in her district, she was able to reopen contracts and institute $3 \%$ pay cuts, but that doesn't mean her actions were easy:

I think the toughest decision on budget cuts is when I've had to lay-off staff, because they have family; they have responsibility. Most of the people live in the community and are part of the community... and to know that I'm affecting their livelihood.

Leadership Resiliency. Resiliency contributes greatly to the tenacity of a superintendent when faced with the challenges of school leadership. Thornton and Sanchez (2010) believed that resilience is complex and multidimensional in nature, describing the complexity of resiliency as a "dynamic process that enables the individual to respond or adapt under adverse situations" (Thornton \& Sanchez, 2010, p. 455). According to I. Prilleltensky and O. Prilleltensky (2006):

Resilience stems, in part, from the capacity and opportunity to understand the role of adversity in one's life and the role of individuals and groups to challenge systems of inequity and discrimination. Coping without challenging these systems may result in accepting the unacceptable. (pp. 91-93)

Bakker and Demerouti (2007) identified the cognitive function of the resilient leader as divergent from those who fail to find success through stressful times. This concept of increased cognitive function and situational understanding develops over time, supporting the development of more effective leadership traits.

Superintendents with a tenacity leadership mindset tended to use deeper approaches and critical strategies to not only improve their performance, but to self-regulate their motivations and 
emotional response to crisis (Robins \& Pals, 2002; Mangels, Butterfield, Lamb, Good, \& Dweck, 2006). One superintendent expressed the importance of emotional self-regulation in leadership, "I think staying positive...that we can do this right now, that we can improve, we can get better. Make the goal real. Make that target real...Keep encouraging them that it can be done." Patterson, Goens, and Reed (2009) concurred, "Even in the toughest of times, educational leaders consistently demonstrate the ability to recover, learn from, and developmentally mature when confronted by chronic or crisis adversity" (p. 11).

Strategies for resilience may involve breaking down long-standing beliefs and eliminating the barriers to success. "If you have good teachers and you are working hard and doing a good job, kids are probably learning," claimed this superintendent, admitting however that they may not be learning the things that are being tested. "You've got to get over it, and you've got to teach the things that are being tested." Another superintendent chided that resiliency could be enhanced by eliminating the stronghold of unions in negotiations:

The administrators need to be able to administrate, not negotiate. Emergency financial outsiders are not needed, the powers they have could help if delegated to administrators who know the district and know what has to be done, but cannot administrate due to contract language.

Building Resilience Capacity in Self and Others. Kouzes and Posner's (2011) claim that leadership is a tenable relationship between leaders and followers is of particular significance when examining the leadership tenacity behaviors of superintendents who act as CEOs of very large school districts with often disparate stakeholders. Kouzes and Posner further contended that these relationships must be multidirectional and ongoing. Resiliency may appear to be an inherent individual trait or disposition, yet, there is evidence that it is a skill that can be developed (Coutu, 2002). One superintendent described his efforts when building resiliency within his staff, "Reassure them that we will have to make some tough choices, but if we work together, we can navigate these difficult times". He went on to endorse "exhibiting confidence through leadership while being sincere and realistic about revenues and expenditures" as a key strategy in building resiliency with stakeholders.

Waxman, Padron, and Gray (2004) believed that leaders with a resiliency lens of understanding seize opportunities to build community and help others increase personal selfefficacy. One of the most critical aspects needed to build resiliency is to build relationships. The effective leader emerges from the failure, conflict or challenge to facilitate change and looks to the challenge only as an opportunity for growth as explained by this superintendent:

It's much more difficult to plan on how many kids you're going to have, especially when you're a school of choice district like us. Half our population is school of choice, which is huge. They could always go back to their resident district at any time. It's very difficult to plan and makes us work harder on keeping our kids, though, and making sure they're happy.

Fullan (2005) endorsed the expenditure of time and energy to build relationships early so that a supportive school environment does not have to be assembled during a time of crisis. 
Leaders with strong resilience capacity are adept at recognizing their weaknesses and finding ways to strengthen these areas. The self-awareness and identification of core beliefs are essential competencies and add to this superintendent's narrative:

This is a period of challenge in our profession, but it is also a time of profound transformation in the field. We are attempting to customize on a mass scale so that every student gets what he/she needs in order to master universal outcomes. Varied inputs and a requirement for universal outputs means we must customize the "treatment" for each student. These are daunting and exciting at the same time.

Superintendents who viewed their leadership as malleable were more open to learning, willing to confront challenges, and capable to recover from failures (Dweck, 1999). In terms of real-time resilience, Reivich and Shatte (2002) suggested that superintendents change counterproductive thoughts into more resilient ones as explained by this superintendent:

We (team effort) have developed a business model that includes new student enrollment, marketing, program/material/facility enhancements and a focus on student achievement. Parents come to us because we are focused on these issues and continue to talk about our strengths. This has allowed us to survive by becoming more efficient in the use of our support cost resources with limited class size increases.

These resilient leaders believed that it was their responsibility to persist in the face of adversity and were more likely to expend unlimited effort and attempt new strategies when faced with economic turmoil, as this superintendent shared, "The students deserve our very best and we are obligated to give it to them, no matter how difficult things may be."

Savvy superintendents with leadership tenacity avoid making the mistakes that undermine confidence in their leadership as well as their personal resilience.

When I took over, morale was absolutely awful. They were not happy. Not that they're real happy now, but ... I'm completely honest. I open up my budget book to everybody and have the union representatives come in and I say, "OK. I have to make cuts. It's going to affect you more than it's going to affect me. You tell me where to make the cuts."

Many superintendents have grown wary of the thought that their only option is to react to external pressures - they want to prevent further degradation of their district, redefining tenacity as their ability to not only cope with conditions related to adversity and injustice, but also that challenge their very existence. Transformational leadership competencies include adaptability, creativity, and perseverance coupled with the will and desire to act with purpose. These are the skills needed to develop set new goals, develop plans, and take incremental steps forward as reflected in this superintendent's response:

What is best for children sometimes conflicts with what is best for adults. It really goes back to the teacher and instruction and to focus on that and have good people. If you want to improve scores, if you want to improve learning, have excellent teachers in your classrooms. 
Reivich and Shatte (2002) claimed that the foundation of resilience is built on the realization that events themselves do not trigger behaviors and emotions, rather superintendents are impacted depending on how they as individuals interpret challenging events. This realization promotes a blending of personal strength and professional mettle to successfully address the challenges of the superintendency.

\section{Conclusion}

The idea that the best leaders are made not born can be extended to the field of education. As seen throughout the study, the impact of experience, conflict and working hard to overcome barriers became critical to the development story of the superintendent. Through adversity, tenacity could be realized and the impact that the superintendent could have on their district increased, even in the face of an economic downturn. As the findings highlighted, the combination of personal traits and experience would result in the realization of effective leadership outcomes. Throughout the study, the impact of the economic downturn was not identified as a critical impact on the role of the educational leader; rather it was considered another variable in the formation of the participant's leadership process.

Through this lens, the idea of effective leadership development can be viewed as a critical byproduct of difficulty in the leadership roles. Dweck (2012) explained that educators should drive a person toward frustration or even to the point of failure in an effort to develop the underling function of resiliency and grit. This same concept can be applied to the educational leader. If not presented with conflict or trials, the leader cannot develop the skills that allow them to succeed in their role as superintendent. Further, Dweck (2012) noted that failure in the face of opposition is a constant.

The acknowledgement of the role and responsibilities of the superintendency, allowed the superintendents to function in an environment that came to experience little change. The stability was further facilitated through the limitations of the leaders within the study and beyond in reflecting on the experiences that were unique to their roles or district. Though this stability was a construct of environment, in many ways showing inability of the role to show variability, it was identified repeatedly by respondents endorsing the stability of the sense of self and role clarification leading to grit and higher levels of leadership tenacity.

Leaders with tenacity support the development of openness to change within the culture of an organization (Groves \& LaRocca, 2011). Groves and LaRocca further explained that openness requires an alignment of personal values and a sense of collective purpose within a change-oriented culture. This study, along with the body of work that defines it, identifies the role of leadership in the educational setting. The findings offer insight to the critical factors of that can lead to the development of effective outcomes for the educational leader. The study begins to inform discourse on leadership within the educational community, breaking down the key factors beyond generalized leadership models to include the nuance of leading a school district during turbulent economic times.

Following this study, further focus must be placed on an effective methodological approach on the reduction of time to bring a superintendent to the level of transformation leader. 
We plan to explore the use of innovative technology and training options to reduce the time required to advance to tenacity leadership. Crisis creates experience; through crisis, effective leaders can advance to tenacity leadership. The issue becomes the identification of effective methods of training and preparation to allow the leader to find this growth and avoid the impacts of a crisis on their community and their school's learning environment.

\section{References}

Bakker, A. B., \& Demerouti, E. (2007). The job demands-resource model: State of the art. Journal of Managerial Psychology, 22, 309-328.

Baum, J. R., \& Locke, E. A. (2004). The relationship of entrepreneurial traits, skill, and motivation to subsequent venture growth. Journal of Applied Psychology, 89, 587-598.

Center for Educational Performance and Information (CEPI). (2005). Registry of educational personnel. Retrieved from https://cepi.state.mi.us/rep/

Center for Educational Performance and Information (CEPI). (2009). 2008-2009 Pupil headcount data. Retrieved from http://www.michigan.gov/cepi/0,4546,7-11321423_30451_30460-214378--,00.html

Center for Educational Performance and Information (CEPI). (2011). Registry of educational personnel. Retrieved from https://cepi.state.mi.us/rep/ 75

Center for Educational Performance and Information (CEPI). (2013). 2012-2013 Pupil headcount data. Retrieved from http://www.michigan.gov/cepi/0,4546,7-11321423_30451_30460-297208--,00.

Coutu, D. (2002). How resilience works. Harvard Business Review, 80(5), 46-48, 50, $52,55$.

DeClerq, D., \& Belausteguigoitia, I. (2017). The usefulness of tenacity in spurring problemfocused voice: The moderating roles of workplace adversity. Journal of Business and Psychology, 32(4), 479-493.

Duckworth, A. Peterson, C., Matthews, M., \& Kelly, D. (2007). Grit: Perseverance and passion for long-term goals. Journal of Personality and Social Psychology, 92(6), 1087-1101.

Dweck, C. S. (2006). Mindset: The new psychology of success. New York, NY: Random House.

Dweck, C. S., \& Grant, H. (2008). Self-theories, goals, and meaning. In J. Y. Shah \& W. L. Gardner (Eds.), Handbook of Motivation Science, 405-416.

Dweck, C. S. (1999). Self-theories: Their role in motivation, personality, and development. Ann Arbor, MI: Psychology Press. 
Dweck, C. S. (2012). Principal Connection / Got Grit? Educational Leadership, 69(6), 84-89.

Ericsson, K. A., Krampe, R. Th., \& Tesch-Romer, C. (1993). The role of deliberate practice I the acquisition of expert performance. Psychological Review, 100, 363-406.

Ericsson, A., \& Pool, R. (2016). PEAK: Secrets from the new science of expertise. New York, NY: Houghton Mifflin/Harcourt.

Finnan, L. A., \& McCord, R. S. (2017) 2016 AASA superintendent salary \& benefits study. Alexandria, VA: AASA The School Superintendents Association.

Fullan, M. (2005). Leadership and sustainability. Thousand Oaks, CA: Corwin.

Gladwell, M. (2008). Outliers: The story of success. New York, NY: Back Bay.

Groves, K. S., \& LaRocca, M. A. (2011). An empirical study of leader ethical values, transformational and transactional leadership, and follower attitudes toward corporate social responsibility. Journal of Business Ethics, 103, 511-528.

Hambrick, D. Z., Oswald, F. L., Altmann, E. M., Meinz, E. J., Gobet, F., \& Campitelli, G. (2014). Deliberate practice: Is that all it takes to become an expert? Intelligence, 45, 3445.

Klocko, B. A., \& Kirby, E. A. (2014). Resiliency: Essential for superintendents and communities during challenging economic times. Journal of Social Sciences Research, 1(1), 58-77.

Kouzes, J. M., \& Posner, B. Z. (Eds.). (2011). Credibility: How leaders gain and lose it, why people demand it (2nd ed.). San Francisco, CA: Jossey-Bass.

Kouzes, B., \& Posner, J. (2012). The leadership challenge: How to make extraordinary things happen in organizations (5th ed.). San Francisco, CA: Jossey-Bass

Mangels, J. A., Butterfield, B., Lamb, J., Good, C., \& Dweck, C. S. (2006). Why do beliefs about intelligence influence learning success? A social cognitive neuroscience model. Social Cognitive Affective Neuroscience, 1(2), 75-86.

Murnieks, C. Y., Cardon, M. S., Sudek, R., White, T. D., \& Brooks, W. T. (2016). The role of passion, tenacity and inspirational leadership in angel investing. Journal of Business Venturing, 31(4), 468-484.

Patterson, J. L., Goens, G. A., \& Reed, D. E. (2009). Resilient leadership for turbulent times: A guide to thriving in the face of adversity. Lanham, MD: Rowman \& Littlefield Education.

Patton, M. Q. (2002). Qualitative research \& evaluation methods (3rd ed.). Thousand Oaks, CA: SAGE. 
Prilleltensky, I. \& Prilleltensky, O. (2007). Promoting well-being: Linking personal, organizational, and community change. Hoboken, NJ: Wiley.

Reivich, K., \& Shatte, A. (2002). The resilience factor:7 keys to finding your inner strength and overcome life's hurdles. New York, NY: Broadway Books

Robins, R. W. \& Pals, J. L. (2002). Implicit self-theories in the academic domain: Implications for goal orientation, attributions, affect, and self-esteem. Self and Identity, 1(4), 313-336.

Shenton, A. K. (2004). Strategies for ensuring trustworthiness in qualitative research projects. Education for Information. 22, 63-75.

Sommers, S. (2009). Measuring resilience potential: An adaptive strategy for organizational crisis planning. Journal of Contingencies and Crisis Management 17(1), 12-23.

Thornton, B., \& Sanchez, J. E. (2010). Promoting resiliency among Native American students to prevent dropouts. Education, 131(2), 455-464.

Waxman, H. C., Padrón, Y. N., \& Gray, J. P. (Eds.). (2004). Educational resiliency: Student, teacher, and school perspectives. Greenwich, CT: Information Age.

\section{Author Biographies}

Barbara A. Klocko, Ph.D. is an associate professor in the Department of Educational Leadership at Central Michigan University. She is a former public school administrator and classroom teacher and currently teaches educational philosophy, action research, and the doctoral seminars. Her research interests include stress and resiliency of educational leaders; models for collaborative leadership; and educational innovation. Barbara.klocko@cmich.edu

Riley Justis, M.A., a doctoral candidate and research assistant at Central Michigan University, brings practical knowledge of educational systems from across the country. As a former superintendent, principal, curriculum director, and teacher, Riley has led innovative initiatives to transform the way in which teaching and learning take place. A passionate innovator, Riley has had an impact on the national conversation about education reform, competency based learning and reflective teaching practices. Justi1rj@cmich.edu

Elizabeth Kirby, Ed.D. is the Senior Associate Dean of the College of Education and Human Services at Central Michigan University in Mt. Pleasant, MI. She spent a decade in public school administration serving as an elementary principal, high school assistant principal, and high school principal. She is recognized as an expert in bullying, school safety, and teen victimization. Her current research interests involve critical incident analysis, resilience, and organizational culture and change. Kirbylea@cmich.edu 